\title{
PREPARATION AND CHARACTERIZATION OF ALKALINE ELECTROLESS Ni-B NANO DEPOSITION ON MILD STEEL IN THE PRESENCE OF AZADIRACHTA INDICA GUM
}

\author{
S. Dheenadhayalan ${ }^{1}$, V. Nijarubini ${ }^{2}$ and J. Mallika ${ }^{1 *}$ \\ ${ }_{1, *}$ Department of Chemistry, PSG College of Arts and Science, \\ Coimbatore - 641 014, (Tamil Nadu) India \\ ${ }^{2}$ Department of Chemistry, Dr. N.G.P Arts and Science College, \\ Coimbatore - 641 048, (Tamil Nadu) India \\ *E-mail : jmchempsg2016@gmail.com
}

\begin{abstract}
The current research work deals with the alkaline electroless Ni-B plating of mild steel in the presence of Azadirachta indica gum (GAI). The deposited Ni-B film on mild steel surface was analyzed using FT-IR and Scanning Electron Microscope (SEM) techniques. The amorphous nature of Ni-B deposits on mild steel was confirmed by XRD. The amount of Nickel and Boron content on deposited Ni-B film on mild steel surface was investigated by Energy Dispersive X-ray Analysis (EDX).
\end{abstract}

Keywords: Electroless Ni-B plating, Azadirachta indica gum, mild steel.

(C) RASĀYAN. All rights reserved

\section{INTRODUCTION}

Based on the nature of the reducing agent used, the electroless nickel coatings ${ }^{1}$ are usually classified into two types namely Ni-P and Ni-B deposits. Nowadays researchers shift more attention towards Ni-B plating because of their widespread acceptance of Ni-P deposit ${ }^{2,3}$. In general, $\mathrm{NaBH}_{4}{ }^{4-10}$ or $\left(\mathrm{CH}_{3}\right)_{2} \mathrm{NHBH}_{3}$ 11-21 were most commonly used as reducing agents for Ni-B plating. The reducing power of $\mathrm{NaBH}_{4}$ is much higher than that of $\left(\mathrm{CH}_{3}\right)_{2} \mathrm{NHBH}_{3}$ and $\mathrm{NaH}_{2} \mathrm{PO}_{2} \cdot \mathrm{H}_{2} \mathrm{O}$.

The Ni-B deposit finds extensive applications than the Ni-P deposit. It is used in aerospace, automotive, electronics, petroleum, and chemical processing due to their high hardness, wear and abrasion resistance and it can replace gold in electronic industries ${ }^{2,24,25}$. Due to the increase of boron content in Ni-B coating, this will cause a rise of the hardness of Ni-B deposits ${ }^{2,22,23}$. The Ni-B deposited mild steel has widespread application in chemical processing, oil and gas production and food processing industries, automobile and in electronic tools ${ }^{26}$.

An electroless nickel plating solution gets decomposed at higher concentration of reducing agent and higher temperature. During the bath decomposition, the rate of evolution of $\mathrm{H}_{2}$ gas is increases and dispersion of finely-divided black precipitate of $\mathrm{Ni}_{2} \mathrm{P}$ or $\mathrm{Ni}_{2} \mathrm{~B}$ occurred in the bath which affects the uniformity and its strength of the coating. Several authors have used thallium nitrate, $\mathrm{Pb}^{2+}, \mathrm{Sn}^{2+}, \mathrm{Hg}^{+}$, $\mathrm{Sb}^{3+}$, 2-mercaptobenzothiazole (2-MBT), maleic and itaconic acid as a stabilizer for Ni-B plating ${ }^{27}$. But the usage of these kinds of stabilizers affects the environment through heavy metal pollution and also their costs are very high.

Therefore the increasing ecological awareness and strict environmental regulations, as well as the inevitable drive towards sustainable and environmentally friendly processes, drew an attention towards the development of non toxic stabilizer.

In the present work the non toxic green stabilizer which is a binary combination of gum exudates of Azadirachta indica (GAI) along with lead nitrate used for electroless Ni-B plating to maintain the bath volume at a higher temperature and increases the stability of the bath at a higher concentration of reducing agent. 


\section{EXPERIMENTAL}

In the Botanical Survey of India (BSI), Coimbatore, Tamil Nadu, India has authenticated the gum exudates of Azadirachta indica A. Juss. Meliaceae. The obtained GAI from the tree was made into a slurry with distilled water and strained through a muslin cloth to remove the suspended impurities. Later, the fine impurities were removed by using quantitative filter paper and kept in a desiccator to obtain a glassy mass of GAI.

\section{Activation of the mild steel surface}

The mild steel specimen of dimension $3 \times 1 \times 0.1 \mathrm{~cm}$ was used for the study. The oxide layer and organic impurities present on the mild steel surface were removed by surface polishing using different grades of emery sheets and then degreased with ethanol. The degreased specimens were dried well and treated with the mixture of sodium hydroxide, sodium phosphate and sodium carbonate at $80^{\circ} \mathrm{C}$ for 5 minutes so as to remove the oily traces from the surface and then washed with distilled water thoroughly to remove all the alkali. The above treated mild steel specimen was then subjected to activation process with $40 \%$ concentrated hydrochloric acid for 5 minutes and then washed with distilled water. The activated mild steel specimens were immediately subjected to the electroless Ni-B plating process.

\section{The composition of the electroless Ni-B plating bath}

The electroless Ni-B plating bath was prepared using $0.5 \mathrm{~g}$ of nickel sulphate, $6.5 \mathrm{~g}$ of sodium potassium tartarate and $0.075 \mathrm{~g}$ of sodium borohyride, $4 \mathrm{~g}$ of sodium hydroxide and $0.1 \mathrm{mg}$ of lead nitrate and 60 ppm of GAI. The electrolytic bath of the above composition prepared using de-ionized water and made up to $100 \mathrm{ml}$. The $\mathrm{pH}(13)$ and temperature $\left(92-95^{\circ} \mathrm{C}\right)$ of the bath solution were kept constant during the electroless plating process. The activated mild steel was immersed in the electrolyte solution for 30 minutes. The coated plates were washed with distilled water, dried and desiccated. The structure, surface morphology and elemental composition of Ni-B deposits were examined by XRD, SEM and EDX.

\section{RESULTS AND DISCUSSION}

The better GAI is obtained from trees that are grown in dry areas. Initially the GAI was found to be transparent, with pale-yellow and it changed to amber or light brown color and finally, it was darkened to brown. GAI dissolves freely in water, giving a light-brown viscous solution. GAI is highly branched polysaccharide and it is reported to contain D- glucose, D-glucoronic acid, L-arabinose, L-fucose, mannose, xylose, rhamnose, D- glucosamine, aldobiuronic acid, serine, threonine and aspartic acid and the ratio of D-galactose to L-arabinose is found to be $3: 2^{28-30}$.

\section{FTIR Characterization of GAI}

The FT-IR spectrum of purified GAI is shown in the (Fig.-1). The characteristic band at $3325-3556 \mathrm{~cm}^{-1}$ are assigned to $-\mathrm{O}-\mathrm{H}$ stretching vibration of alcoholic group and band at $2530-3186 \mathrm{~cm}^{-1}$ is due to $-\mathrm{O}-\mathrm{H}$ stretching vibration of $-\mathrm{COOH}$ group of GAI. The carbonyl stretching vibration of $-\mathrm{COOH}$ group is seen at $1681 \mathrm{~cm}^{-1}$. The symmetric $-\mathrm{C}-\mathrm{O}$ stretching vibrations of alcoholic groups are seen at 1041 and 1134 $\mathrm{cm}^{-1}$. The weak $-\mathrm{N}-\mathrm{H}$ symmetric stretching and bending vibration of amine group appears at $3425 \mathrm{~cm}^{-1}$ and $1651 \mathrm{~cm}^{-1}$.

\section{Role of GAI in Electroless Ni-B Plating SEM Analysis}

The maintenance of bath volume at a higher temperature in electroless Ni-B is highly challenging. The decrease of volume at higher temperature affects the uniformity of coating which may reduce the strength of the coating. The SEM image (Fig.-2b) shows the lack of uniformity and nodular grains with a different size of Ni-B deposits. This is mainly due to loss of water molecule by evaporation at a higher temperature. The uniform and fine deposit is achieved by the addition of GAI. The SEM image of (Fig.2c) shows a uniform distribution of Ni-B nodules and the surface exhibits a cauliflower-like structure 
with almost very smaller grain size. This may be due to the presence of GAI, performing a dual role in the electroless Ni-B plating bath.

i. It forms intermolecular hydrogen bonding with water molecules and prevents the escape of water as water vapor.

ii. Also, it forms an intermolecular hydrogen bond with the bidentate tartarate ligand of Nitartarate complex (Fig.-3) providing a uniform distribution of Ni complex along the surface of the mild steel.

In the presence and the absence of GAI treated Ni-B deposition, the particle size of the Ni-B deposit is found to be less than $100 \mathrm{~nm}$.

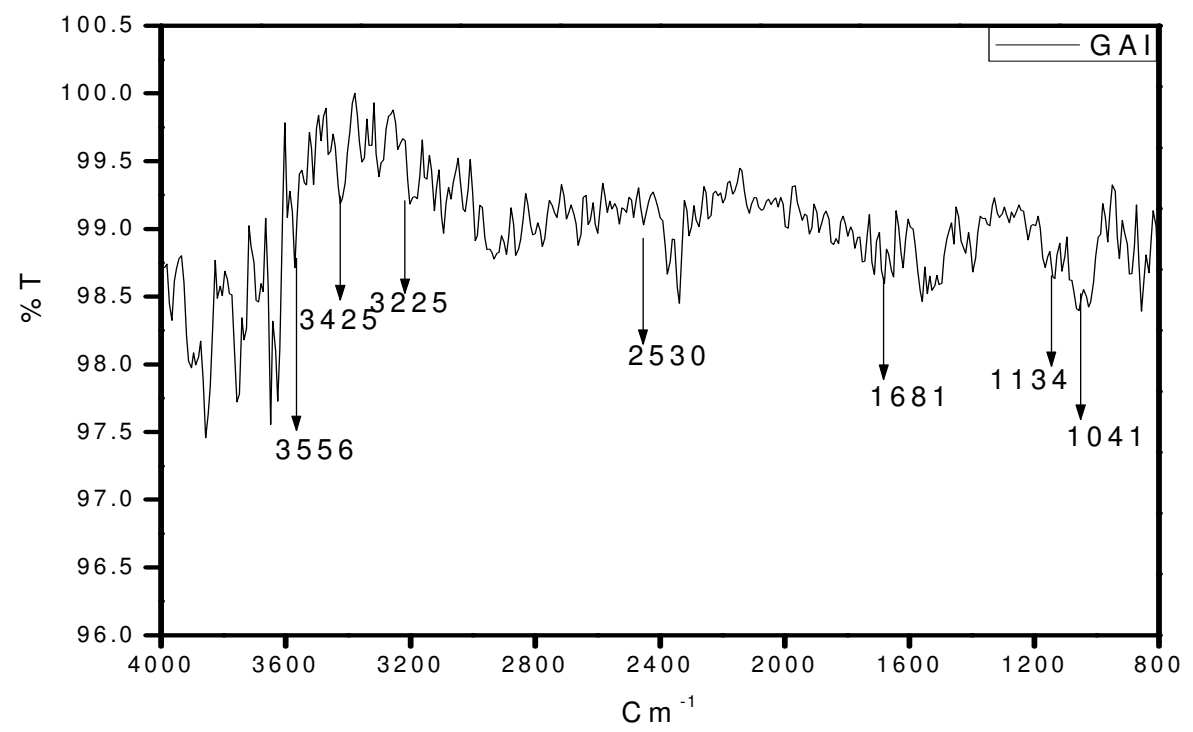

\section{EDX Analysis}

Fig.-1: FTIR spectrum of Azadirachta indica gum (GAI)

The elemental composition of Nickel and Boron in Ni-B coated mild steel was determined by Energy Dispersive X-ray Analysis (Fig.-2a, 2b, 2c). The amount of Nickel and Boron content in Ni-B coated mild steel shows $3.33 \%$ wt of $\mathrm{Ni}$ and $20.29 \%$ wt of B and the GAI treated Ni-B coated mild steel shows $1.63 \%$ wt of $\mathrm{Ni}$ and $16.75 \%$ wt of B. The decreasing amount of Nickel and Boron content in Ni-B coated mild steel in the presence of GAI is mainly due to the slow release of nickel ion for reduction reaction. The viscous nature of GAI reduces the fast migration of Ni ions towards the mild steel surface (Fig.-3) resulting in uniform distribution of nano Ni-B film over the surface.
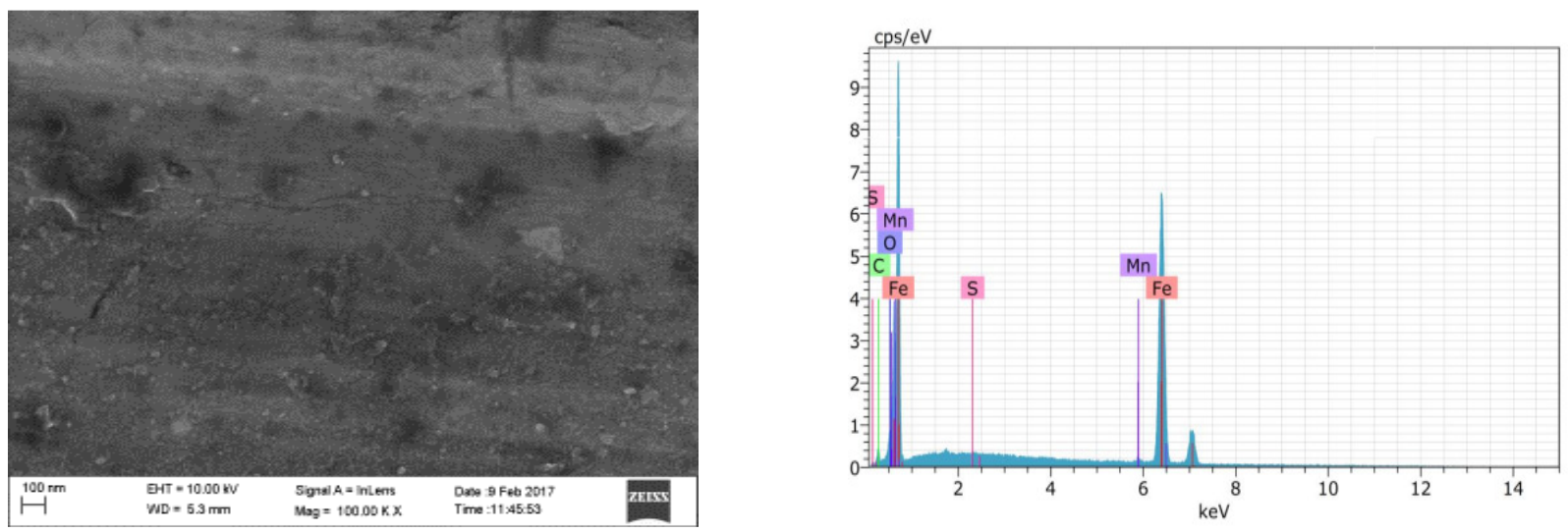

Fig.-2a: SEM and EDX image of mild steel 

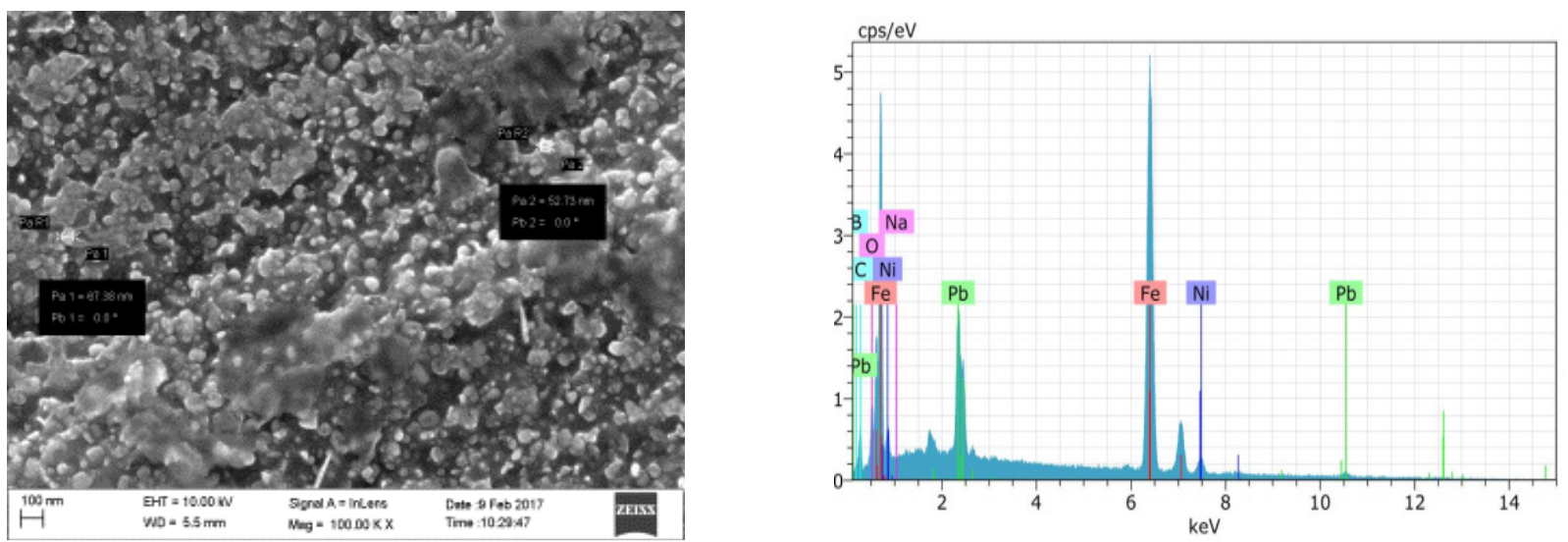

Fig.-2b: SEM and EDX image of Ni-B coated mild steel (Absence of GAI)
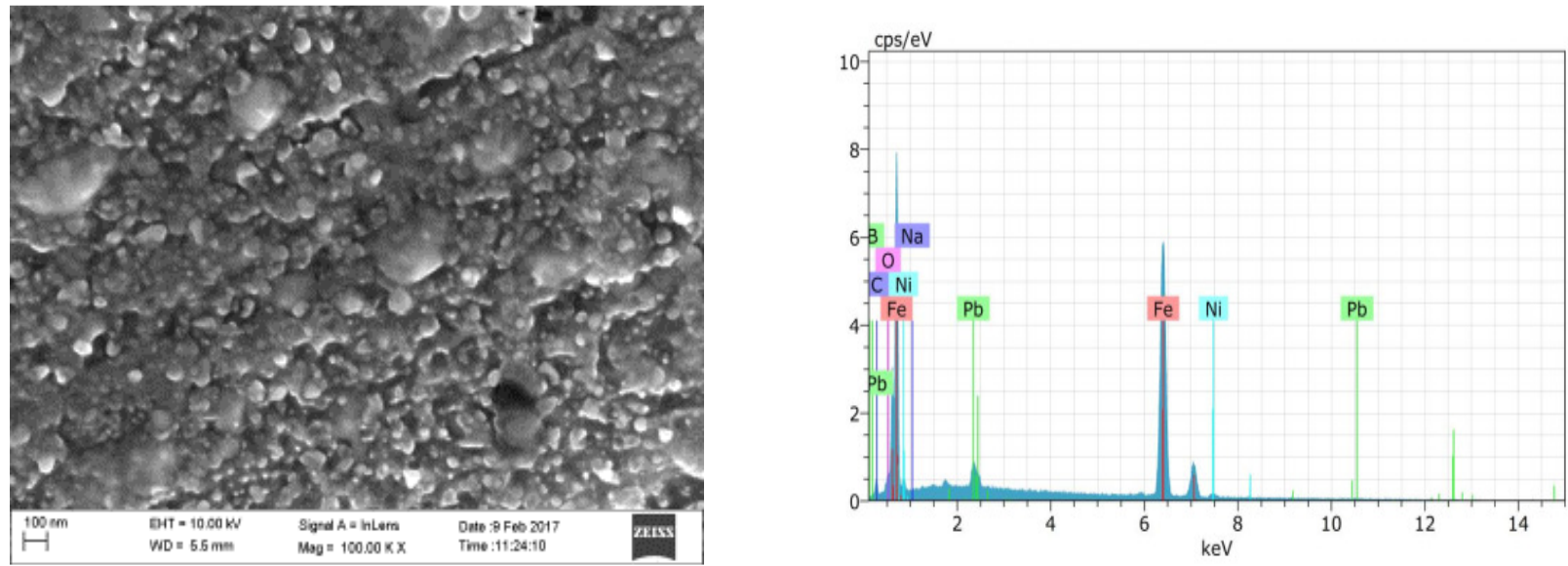

Fig. -2c: SEM and EDX image of Ni-B coated mild steel (Presence of GAI)

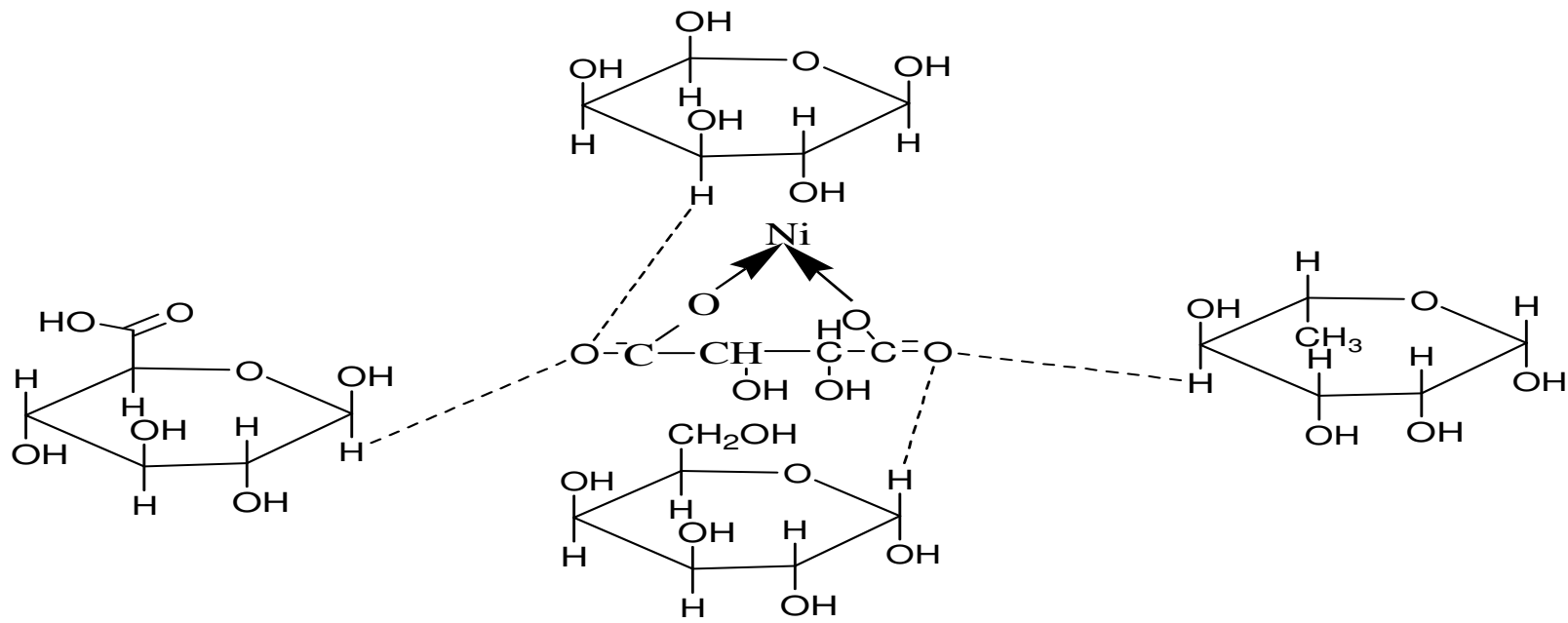

Fig.-3: Schematic representation of intermolecular molecular hydrogen bonding of GAI with Ni-tartarate complex

\section{XRD Analysis}

XRD exhibits a single broad peak for Ni-B coated mild steel which indicates the amorphous nature of Ni$\mathrm{B}$ deposits on mild steel (Fig.-4). The Ni-B coated mild steel shows a strong diffraction peak at $2 \theta=$ $44.68^{\circ}$ and GAI treated Ni-B coated mild steel shows at $2 \theta=44.67^{\circ}$, which is the characteristic peak of 
Nickel and it is attributed to (111) plane of metallic nickel. This proves the deposition of metallic nickel on mild steel surface ${ }^{22,26}$. The crystallite size of the $\mathrm{Ni}-\mathrm{B}$ deposits was calculated using the formula:

$$
D=K \lambda / \beta \operatorname{Cos} \theta
$$

Where, $\mathrm{D}, \beta, \lambda$ and $\theta$ represents the grain size, full width at half maximum (FWHM) of the diffraction peak, wavelength of an incidental $\mathrm{Cu} \mathrm{K} \alpha \mathrm{X}$-ray and diffraction angle respectively. The calculated values for Ni-B deposit in the absence and presence of GAI treated Ni-B coated mild steel are 70 and $77 \mathrm{~nm}$ respectively.

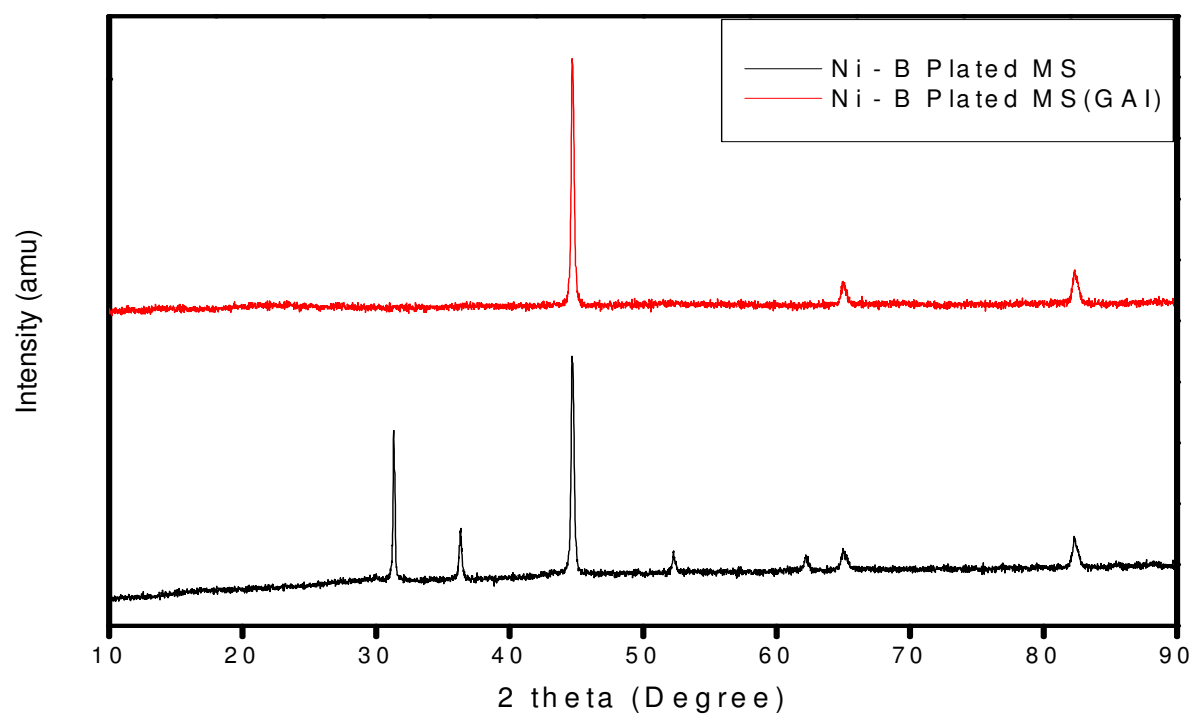

Fig.- 4: XRD pattern of Ni-B coated mild steel

\section{CONCLUSION}

The alkaline electroless Ni-B nano coating on mild steel surface was achieved with the gum exudates of Azadirachta indica (GAI). The gum provides a uniform and fine deposit of nano Ni-B coating on mild steel surface and also prevents the rate of vaporization of bath solution at a higher temperature.

\section{REFERENCES}

1. A. Brenner, and G. Riddell, Journal of Research, 31, 37 (1946)

2. V. Vitry, A.F. Kanta and F. Delaunois, Materials Science and Engineering B, 175, 266 (2010), DOI:10.1016/j.mseb.2010.08.003

3. B. Oraon, G. Majumdar, and B. Ghosh, Materials and Design, 29, 1412 (2008), DOI:10.1016/j.matdes.2007.09.005

4. I. Baskaran, T. S. N. Sankara Narayanan and A. Stephen, The International journal of surface engineering and coatings, 87, 221 (2009), DOI:10.1179/174591909X438848

5. A. R. Di Giampaolo, J. G. Ordonez, J. M. Gugliemacci and J. Lira, Surface and Coatings Technology, 89, 127 (1997), DOI:10.1016/S0257-8972(96)03089-7

6. A. F. Kanta, V. Vitry and F. Delaunois, Materials Letters, 63, 2662 (2009), DOI:10.1016/j.matlet.2009.09.031

7. Z. C. Wang, F. Jia, L. Yu, Z. B. Qi, Y. Tang and G. L. Song, Surface \& Coatings Technology, 206, 3676 (2012), DOI:10.1016/j.surfcoat.2012.03.020

8. F. Delaunois, J. P. Petitjean, P. Lienard and M. Jacob-Duliere, Surface and Coatings Technology, 124, 201 (2000), DOI:10.1016/S0257-8972(99)00621-0 
RASĀYAN J. Chem.

Vol. 11 | No. 2 |634 - 639 | April - June | 2018

9. Beril Kaya, Turgut Gulmez and Mehmet Demirkol, IAENG Transaction on Engineering Technologies, 2, 62 (2009), DOI:10.1063/1.3146199

10. K. Krishnaveni, T. S. N. Sankara Narayanan and S. K. Seshadri, Synthesis and Reactivity in Inorganic, Metal-Organic and Nano Metal Chemistry, 42, 920 (2012), DOI: $10.1080 / 15533174.2011 .618475$

11. G. Mallory, Plating, 58, 319 (1971)

12. M. Lelental, Journal of Electrochemical Socitey, 120, 1650 (1973), DOI:10.1149/1.2403322

13. Susumu Arai, Yuzo Imoto, Yosuke Suzuki and Morinobu Endo, Carbon, 49, 1484 (2011), DOI:10.1016/j.carbon.2010.12.019

14. A. Chiba, H. Haijima, W. C. Wu, Ultrasonics, 42, 617 (2004), DOI:10.1016/j.ultras.2004.01.084

15. A. Chiba, H. Haijima, K. Kobayashi, Surface and Coatings Technology, 169-170, 104 (2003), DOI:10.1016/S0257-8972(03)00171-3

16. Shinji Yae, Keisuke Sakabe, Naoki Fukumuro, Susumu Sakamoto, Hitoshi Matsuda, Journal of The Electrochemical Society, 158(9), D573 (2011)7, DOI:10.11491/1.3610221

17. M. V. Ivanov, Protection of Metals, 37(6), 592 (2001), DOI: 10.1023/A:1012827932615

18. Manabu Tsujimura, Hiroaki Inoue, Hirokazu Ezawa, Masahiro Miyata, Masahiro Ota, Materials Transactions, 43 (7), 1615 (2002), DOI:10.2320/matertrans.43.1615

19. M. Velez, H. Quiones, A. R. Di Giampaolo, J. Lira and I. C. Grigorescu, International Journal of Refractory Metals \& Hard Materials, 17, 99 (1999), DOI: 10.1016/S0263-4368(98)00035-3

20. H. B. Hassan and Z. Abdel Hamid, International Journal of Hydrogen Energy, 36(8), 5117 (2011), DOI:10.1016/j.ijhydene.2011.01.024

21. Sen-lin Wang, Thin Solid Films, 515, 8419 (2007), DOI:10.1016/j.tsf.2007.05.066

22. Suman Kalyan Das and Prasanta Sahoo, Advances in Mechanical Engineering, 2012, 1 (2012), DOI:10.1155/2012/703168

23. Mustafa Anik, Erhan Korpe and Esin Sen, Surface and Coatings Technology, 202, 1718 (2008), DOI:10.1016/j.surfcoat.2007.07.031

24. K. Krishnaveni, T. S. N. Sankara Narayanan, S. K. Seshadri, Surface and Coatings Technology, 190, 115 (2005), DOI:10.1016/j.surfcoat.2004.01.038

25. R. N. Duncan, R.N and T. L. Arney, Plating Surface Finsh, 71, 49 (1984)

26. K. N. Srinivasan, R. Meenakshi, A. Santhi, P. R. Thangavelu, and S. John, Surface Engineering, 26(3), 153 (2010), DOI: 10.1179/174324409x409468

27. Carlos Dominguez-Rios, Abel Hurtado-Macias, Roal Torres-Sanchez, Manuel A Ramos and Jesus Gonzalez-Hernandez, Industrial \& Engineering Chemistry Research, 51, 2012 (7762), DOI:10.1021/ie201760g

28. Amos Nussinovitch, Plant Gum Exudates of the World: Sources, Distribution, Properties, and Applications, CRC Press, Taylor \& Francis group, p.93, (2010).

29. T. Brindha and J. Mallika, International Journal of Pharmaceutical Chemistry, 05(06), 227 (2015), DOI:10.7439/ijpc

30. D. M. W. Anderson and Hendrie A, Carbohydrate Research, 20 (2), 259, (1971), DOI: 10.1016/S0008-6215(00)81379-8

[RJC-2085/2018] 